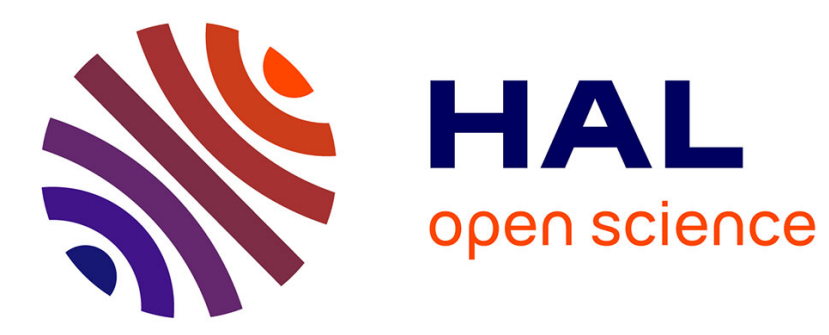

\title{
Estimation of radiation doses delivered by Terrestrial Gamma ray Flashes within leader-based production models
}

M. Pallu, Sébastien Celestin, Francois Trompier, Michel Klerlein

\section{- To cite this version:}

M. Pallu, Sébastien Celestin, Francois Trompier, Michel Klerlein. Estimation of radiation doses delivered by Terrestrial Gamma ray Flashes within leader-based production models. Journal of Geophysical Research: Atmospheres, 2021, 126 (8), pp.e2020JD033907. 10.1029/2020JD033907 . insu-03177542

\section{HAL Id: insu-03177542 \\ https://hal-insu.archives-ouvertes.fr/insu-03177542}

Submitted on 23 Mar 2021

HAL is a multi-disciplinary open access archive for the deposit and dissemination of scientific research documents, whether they are published or not. The documents may come from teaching and research institutions in France or abroad, or from public or private research centers.
L'archive ouverte pluridisciplinaire HAL, est destinée au dépôt et à la diffusion de documents scientifiques de niveau recherche, publiés ou non, émanant des établissements d'enseignement et de recherche français ou étrangers, des laboratoires publics ou privés. 


\title{
Estimation of radiation doses delivered by Terrestrial Gamma ray Flashes within leader-based production models
}

\author{
M. Pallu ${ }^{1,2}$, S. Celestin ${ }^{1}$, F. Trompier ${ }^{3}$, and M. Klerlein ${ }^{2}$ \\ ${ }^{1}$ LPC2E, University of Orleans, CNRS, Orleans, France \\ ${ }^{2}$ Occupational Health Services, Air France, Roissy-en-France, France \\ ${ }^{3}$ Institute of Radiation Protection and Nuclear Safety (IRSN), Fontenay-aux-Roses, France
}

\section{Key Points:}

- Radiation doses associated with runaway electrons producing TGFs may exceed usual safety annual limits

- The highest doses from electrons are delivered in very compact regions

- Photons produce radiation doses that do not exceed safety limits, but over areas wide of several kilometers and secondary electrons produce negligible radiation doses

Corresponding author: M. Pallu, melody.pallu@cnrs-orleans.fr

This article has been accepted for publication and $\bar{c}^{-}$undergone full peer review but has not been through the copyediting, typesetting, pagination and proofreading process, which may lead to differences between this version and the Version of Record. Please cite this article as doi: 10.1029/2020JD033907.

This article is protected by copyright. All rights reserved. 


\section{Abstract}

With a typical production altitude of $\sim 12 \mathrm{~km}$, Terrestrial Gamma ray Flash (TGF) sources are close to commercial flight altitudes, and these events could potentially be an unforeseen exposure to ionizing radiation for aircraft passengers and crews. Dwyer et al. (2010) estimated the dose that a TGF could produce, and showed that TGFs in principle could be an additional non-negligible factor to the exposure for aircraft passengers. The regulations for aircrew protection against radiation, only consider the radiation of galactic and solar origin (ICRP, 2007; Bottollier-Depois et al., 2012). Other possible sources of exposure, such as TGFs, are not yet considered, mainly because of the lack of reliable data on possible dose level and on the probability for an airplane to be in the vicinity of such an event. In order to improve the evaluation of the TGF exposure level and associated risks, and as there is still a divergence of opinion about the exact source mechanisms, we present calculations of doses produced by high-energy electrons in TGF sources, within two different lightning leader-based production models: (1) a pure lightning leader model and (2) considering further avalanches in a homogeneous electric field region. We find that although the doses from photon and secondary electron beams are weak, the dose potentially received by passengers inside the TGF electron source regions may be very high $(>20 \mathrm{mSv})$. The results reported in the present paper call for a need to perform a thorough risk assessment including the probability for an aircraft to be in a TGF source region.

\section{Introduction}

Terrestrial Gamma-ray Flashes (TGFs) are bursts of high-energy photons first reported in 1994 with the Compton Gamma-Ray Observatory (Fishman et al., 1994). They last less than 1 millisecond (Fishman et al., 2011; Marisaldi et al., 2015) and single photons can reach more than $40 \mathrm{MeV}$ in energy (Briggs et al., 2010; Marisaldi et al., 2010). They are produced at an altitude of $\sim 12 \mathrm{~km}$ (Lu et al., 2010; Cummer et al., 2011, 2014, 2015). From the start, these events have been known to be correlated with thunderstorm activity (Fishman et al., 1994), and we now know that they are associated with a common type of lightning discharges, namely normal polarity intracloud discharges that transport negative charges upward (+IC) (Stanley et al., 2006; Lu et al., 2010). TGFs are very bright, with a fluence up to $\sim 1$ photon $/ \mathrm{cm}^{2}$ when observed from a 500 kilometers or- 
bit (e.g., Briggs et al., 2010) and quite frequent as their occurrence rate is estimated to be 400,000 per year, only for those events observable by Fermi-GBM (Briggs et al., 2013).

stgaard et al. (2012) estimate that detectable TGFs such as those considered in the present study are produced by over $2 \%$ of intra-cloud (IC) lightning discharges, which lightning type represents about $75 \%$ of all lightning, and that it cannot yet be excluded that all lightning could produce TGFs too dim to be detected from satellite. Briggs et al. (2013) estimate a TGF occurrence rate of 400,000 per year for TGFs detectable by the Fermi-GBM corresponding to 1/2600 TGF per lightning optically detected from space. Significant research effort has been recently focused on dim TGFs, not necessarily detectable from space, but corresponding to photon counts statistically correlated to groundbased lightning detection as proposed by Smith et al. (2014). The results of these studies depend on the considered satellite detector and the ground-based lightning detection network used. They lead to different effective statistical thresholds. McTague et al. (2015) found that TGFs occur between $1 / 40$ and 1/500 of IC discharges over the continental US using Fermi and stgaard et al. (2015) found a TGF-IC ratio of 1/1900-1/1600 through comparison of RHESSI and WWLLN data, but speculated that a large population of weaker TGFs may exist. Also using RHESSI and WWLLN, Smith et al. (2016) concluded that less than $1 \%$ of lightning are coincident with TGFs. Using a larger data set, Albrechtsen et al. (2019) found that $0.71 \%$ of IC discharges produce TGFs leading to 3 or more counts in RHESSI detectors. In summary, the frequency of dim TGFs leading to less than one photon in usual satellite detectors is still unknown. However, for stronger TGFs, such as those the present work is based on, published studies place the TGF-IC lightning ratio to a level slightly lower than $1 \%$.

Currently, the exact production mechanism of TGFs remains uncertain. Several models have been proposed, but nearly all agree on the fact that processes related to relativistic runaway electron avalanches (RREAs) explain fluences and spectra observed by satellites (e.g., Dwyer et al., 2012). In the atmosphere, an electric field exceeding the minimum ionizing particle (MIP) energy loss rate $\left(\sim 210 \mathrm{keV} \cdot \mathrm{m}^{-1}\right.$ at ground level (Berger et al., 2016)) is necessary to give more energy to the electrons than they lose through collisions. In fact, because of electron scattering the runaway threshold electric field is slightly higher: $E_{t h}=280 \mathrm{kV} \cdot \mathrm{m}^{-1}$ (Dwyer, 2003). Electrons with sufficiently high energy thus become runaway electrons, hence accelerating under a given electric field while still colliding with air molecules (Wilson, 1925). Rarely, secondary electrons produced 
will also be runaway electrons, accelerate, and knock off new electrons. This then forms runaway electron avalanches, called RREAs. There is a divergence of opinion about how RREAs are initiated. Three models exist: (1) the pure leader model (e.g., Xu et al., 2012; Celestin et al., 2015), (2) production of seed runaway electrons by a leader with further RREAs in ambient field $>E_{t h}$ (Dwyer, 2008), and (3) relativistic feedback accompanied with a leader or not (Dwyer, 2003; Liu \& Dwyer, 2013; Khn et al., 2017). However, recent publications related to the contemporary ASIM mission have suggested the streamerleader origin of TGFs by showing that all of the TGFs studied in their work were associated with an optical emission. (Heumesser et al., 2020; Khn et al., 2020). In our paper, we focus on the two first models. In the context of those two models, the RREA beam radius, and hence, fluxes and doses, are well-defined.

Given the high-energy nature and the mean production altitude of these events, in addition to possible effects on avionics (Tavani et al., 2013), it seems reasonable to think that TGFs could potentially deliver non-negligible doses at typical commercial flight altitudes. A first estimation of the doses produced by runaway electrons was reported by Dwyer et al. (2010). They indicated that, depending on the radius of the runaway electron beam, TGF doses might approach or even exceed annual safety limits.

Nowadays, when mandatory by national regulations, an evaluation of the exposure in terms of effective dose is usually made for each aircrew. The dose evaluations are performed as for all other certified services of individual monitoring sometimes using passive dosimetry but usually using calculation tools for aircrews, individual aircrew doses being reported monthly at minimum. Monitoring systems calculate the effective dose for each and every flight using when possible real flight route information, individual exposure being the sum of doses for flights listed for a given aircrew. These certified calculation tools take into account the solar modulation for the Galactic Cosmic Rays (GCR) flux and also contribution of Solar Energetic Proton (SEP) events (e.g., Clairand et al., 2009; Bottollier-Depois et al., 2012). Compared to routine individual dosimetry services with passive dosimeters, this unique approach used for aircrew dosimetry is far more efficient: doses are directly evaluated in terms of effective dose in which annual limits are expressed, costs are reduced, including the cost of lost dosimeters, and there is no issue with the problem of dosimeter detection limit or background doses. International recommendation and most of national regulations imposed a limit at $20 \mathrm{mSv}$ over the last 12 months for the exposed workers. In several countries, aircrews having an exposure 
above $1 \mathrm{mSv}$ on a consecutive 12-month period are considered as exposed workers and individual dose monitoring is therefore mandatory. For European airlines, the highest aircrew exposure remains below $6 \mathrm{mSv}$.

However, as a recently discovered phenomenon, TGFs are not included in these evaluations. Actually, since aircrew doses are assessed by calculations, very few in-flight measurement monitoring programs exist. Those existing are focusing on the measurement of SEP events with instrumentation not adapted to high energy bursts of X-rays or energetic electrons. Therefore, no measured data on doses due to TGF are available, especially in real airline operation conditions. At aircraft altitudes, only two TGFs have been detected so far (Smith et al., 2011; Bowers et al., 2018), none of them in the direct beam. The few data from dedicated flight campaigns around thunderstorms are not sufficient to assess the exposure and risk for aircrew (e.g., Trompier et al., 2014). Simulations are obviously the most pragmatic approach for providing a first dose evaluation per event. The probability to be exposed is another key point that will not be easy to solve. Moreover, for the calculations, due to the number of models and the number of relevant parameters in the calculation, intercomparisons will be necessary to evaluate the reliability of these estimations. A similar approach is in progress in the frame of Eurados (the European Radiation Dosimetry Group) regarding the dose evaluation of SEP events that exhibit large discrepancy depending on methods or models (Bottollier-Depois et al., 2012). In the case of TGFs, the exposure being localized and very short compared to SEP events, assessing the associated risks as closely as possible with airline operating conditions, will require to collect a large amount of data with new in-flight measurement monitoring programs. Simulation and flight measurement studies are necessary to evaluate the need to take TGFs into account as a new possible source of exposure. Nevertheless, if TGF doses are assessed to be significant, this could challenge the paradigm of dose evaluation for an aircrew. As a consequence, the implementation of measurement systems for on-board re-routing strategies, or individual dosimeters might be required. This could end up as significant costs for airlines, with additional lower performances, and higher uncertainties for individual dosimetry.

In the present work, we calculate the radiation doses produced by runaway electrons in RREAs using two different production models (Sections 2.2 and 3.1 for the first model, and 2.3 and 3.2 for the second model) and the radiation dose delivered by photons and secondary electrons (Sections 2.4 and 3.3). A discussion of the effect of the air- 
craft cabin on the doses delivered by particles associated with TGFs is presented Section 4.3. Figure 1 illustrates the basic situation we focus on in this work: we use a source altitude of $12 \mathrm{~km}$, which is typical for TGFs. We will estimate doses for altitudes ranging from 12 to $13 \mathrm{~km}$ for electrons and from 13 to $20 \mathrm{~km}$ for gamma rays. The main hypothesis of this study is the production of $10^{18}$ photons at the TGF source, which is considered as a bright TGF as supported by satellite measurements (e. g., Gjesteland et al., 2015; Mailyan et al., 2016, 2019). This assumption is discussed further in Section 4.2.

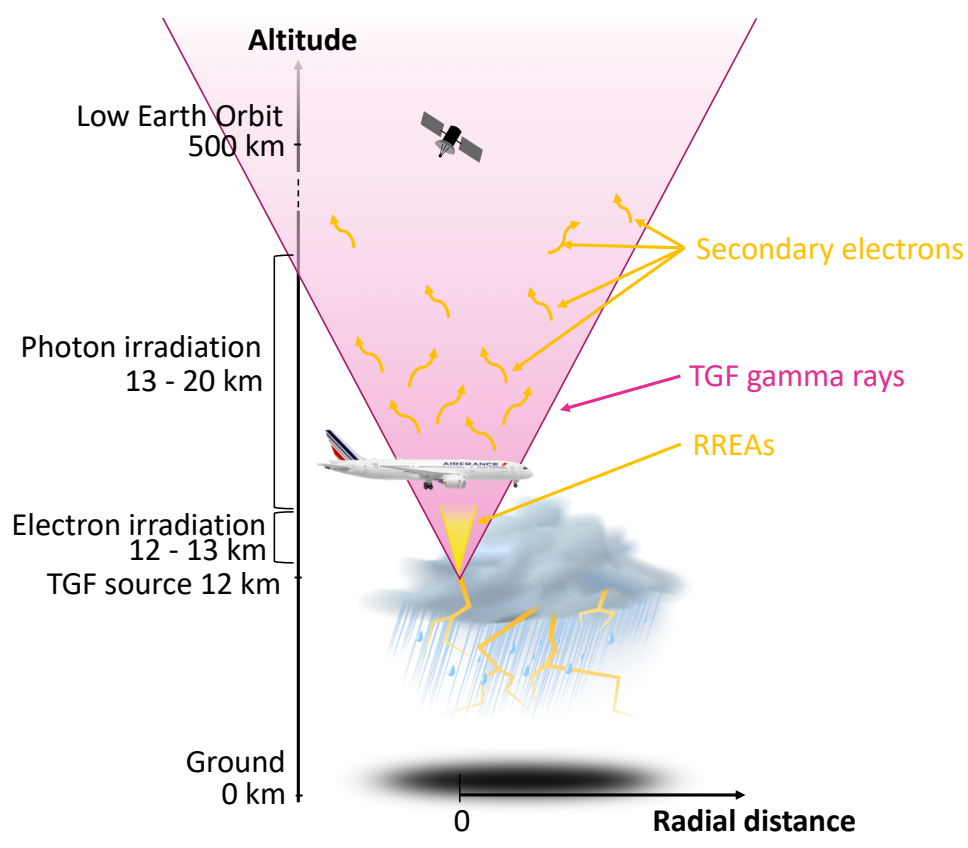

Figure 1. Representation of the situation studied in this work. The pink area represents the TGF, while the yellow area is the location of causative RREAs. Secondary electrons are electrons produced by collisions between TGF photons and air molecules.

\section{Methods}

\subsection{Radiation dose calculation}

In radioprotection, a quantity named absorbed dose quantifies the energy deposited by ionizing radiation per mass unit in matter and is expressed in grays (Gy). Two quantities are defined to quantify the associated health hazard. The first one, called effective dose, is a protection quantity in which the exposure limits are expressed. This quantity is calculated by summing the absorbed dose in organs weighted by coefficients that 
take into account the variability of organ sensitivity to ionizing radiation and the variability of biological effects of the different radiation types. The second is an operational quantity used to estimate the effective dose through measurements. It is named ambient dose equivalent, noted $H^{*}(10)$, and is defined by the absorbed dose that would be deposited by the corresponding expanded and aligned radiation field into a 30-cm diameter sphere made of tissue-equivalent material (ICRU sphere) at a 10-mm depth on the radius opposing the direction of the aligned radiation field, taking into account the radiation type. Both these quantities are measured in sieverts (Sv) (ICRP, 2007)

Doses can be calculated from the radiation fluence, which is the number of particles going through a surface per unit area. It corresponds to a flux integrated over time. To go from a fluence to a dose in the present work, we use fluence-to-dose conversion coefficients (units: $\mathrm{Sv} \cdot \mathrm{cm}^{2}$ ) from the Fluka database (Pelliccioni, 2000). In particular, we use photon and electron coefficients. These coefficients are shown as a function of particle energy in Figure 2. Ambient dose equivalent coefficients are in solid lines for electrons (in blue) and photons (in magenta). The three other lines are effective doses for different exposure geometries: anteroposterior (AP), isotropic (Iso), and from the top (Top). These coefficients take into account the danger related to the type of radiation received and also the sensitivity of the irradiated tissue.

For the sake of reproducibility and comparison to measurements, in this paper we mainly focus on the ambient dose equivalent $H^{*}(10)$ :

$$
H^{*}(10)=\int_{\varepsilon_{\min }}^{+\infty} f_{H^{*}}(\varepsilon) \cdot \phi(\varepsilon) \cdot d \varepsilon
$$

where $\varepsilon_{\min }$ is the minimum energy considered, $\phi(\varepsilon)$ is the fluence of electrons or photons as a function of the energy $\varepsilon$, and $f_{H^{*}}$ is the fluence-to-ambient dose equivalent conversion coefficient for electrons or photons (see Figure 2). For the energy range of interest here, effective doses Iso and AP are on the same order of magnitudes as $H^{*}(10)$ (see Figure 2).

To go from the electron fluence to the ambient dose equivalent, one can use a conversion factor $h$ that is calculated as follows:

$$
h=\int_{\varepsilon_{\min }}^{+\infty} f(\varepsilon) f_{H^{*}}(\varepsilon) d \varepsilon
$$

where $f(\varepsilon)$ is the normalized RREA spectrum (integration of $f(\varepsilon)$ over the energy range equals one) such that $\phi(\varepsilon)=\varphi \cdot f(\varepsilon)$, where $\varphi$ is the total fluence, and $f_{H^{*}}$ is the fluence- 


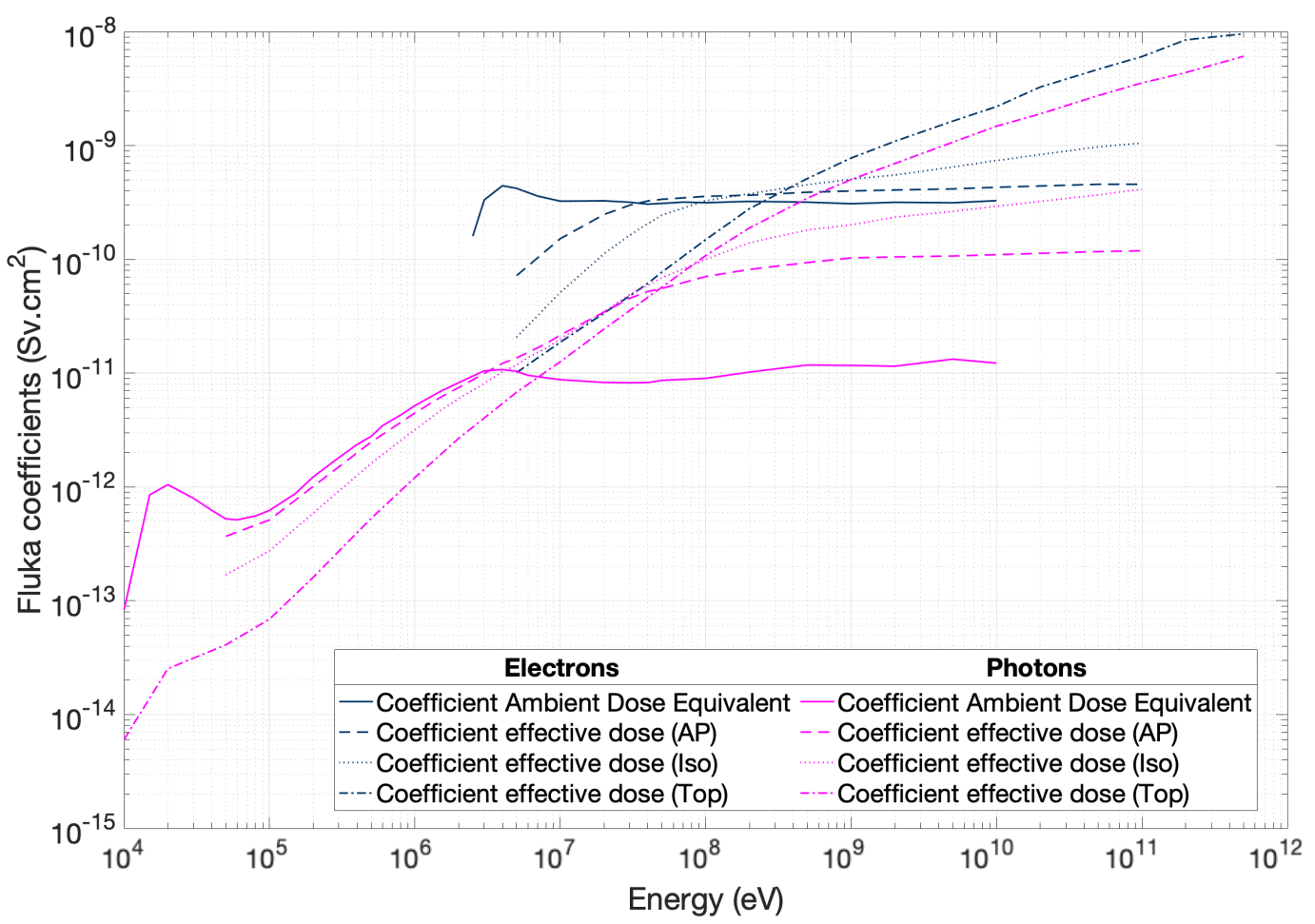

Figure 2. Fluence-to-dose conversion coefficients as a function of the energy, used to calculate doses in the present paper. Data are obtained from the Fluka database (Pelliccioni, 2000). The coefficients used in this paper are $f_{H^{*}(10)}$, the ambient dose equivalent coefficients.

to-ambient dose equivalent conversion coefficients for electrons (see Figure 2 ) ; $h$ is therefore a constant. Hence, one obtains $H^{*}(10)=h \cdot \varphi$, where $h$ was found to be $3 \cdot 10^{-14}$ $\mathrm{Sv} \cdot \mathrm{m}^{2}$ for the ambient dose equivalent. For the sake of comparison, the value of $h$ found in this paper is consistent with that found in (Dwyer et al., 2010) for an effective dose in anteroposterior direction $\left(h_{E} \sim 9 \cdot 10^{-15} \mathrm{~Sv} \cdot \mathrm{m}^{2}\right)$.

\subsection{Pure leader model}

In the pure leader model, we assume that electrons are accelerated in the high and inhomogeneous electric field created by a leader tip without further acceleration in the ambient field. We use a 3-D relativistic Monte Carlo model to simulate the propagation of electrons in air ( $80 \%$ of $\mathrm{N}_{2}$ and $20 \%$ of $\mathrm{O}_{2}$ ), capable of simulating electrons from sub$\mathrm{eV}$ to GeVs (Celestin \& Pasko, 2011). The electric field depends on the length $l$ of the leader channel immersed in an ambient electric field $E_{0}<E_{t h}$. The quantity $E_{t h} \approx$ $284 \mathrm{kV} \cdot \mathrm{m}^{-1}$ is the threshold electric field for producing RREAs at ground level (e.g., Dwyer, 
2003). Assuming that the leader channel is an equipotential, the electric field in the vicinity of the leader tip is calculated through the method of moments (Balanis, 1989). This method implies that the electric field is not yet shielded by the developing streamers in our simulations (see discussion in Celestin and Pasko (2011)). The energies of secondary electrons are obtained from the ionization differential cross section, calculated through the relativistic binary-encounter-Bethe model (Kim et al., 2000; Celestin \& Pasko, 2010). The relativistic equations of conservation of momentum and energy give the scattering angles of primary and secondary electrons, considering that the formed ion is static. A continuous radiative friction of electrons due to bremsstrahlung (Berger et al., 2005) is also implemented. It becomes significant for electrons with energy on the order of a few $10 \mathrm{~s}$ of $\mathrm{MeV}$ or more.

In this work, we assume that the lightning leader produces a potentiel drop of 300 MV. This potential drop allows for RREAs to develop fully and reach a typical spectrum with an exponential cutoff (see Celestin et al., 2015).

Criticisms and constraints about such model have been expressed in (Skeltved et al., 2017). Celestin and Pasko (2011) and Skeltved et al. (2017) argue that the static vacuum solution overestimates the maximum electric field and that it should be limited to a magnitude of $50 \mathrm{kV} \cdot \mathrm{cm}^{-1}$. This maximum field is also constrained by the time scale of increase of the electric field in front of a new leader branch during leader-stepping [see Celestin and Pasko (2011), Figure 7]. Based on the dynamic streamer production process at the tip of the lightning leader (Bazelyan \& Raizer, 2000) pp. 6768], Celestin and Pasko (2011) also argued that $50 \mathrm{kV} \cdot \mathrm{cm}^{-1}$ was a reasonable assumption on the maximum of the electric field amplitude. It must be noted that the latter argument is based on the hypothesis of a steady streamer production. Fast potential increase in the newly created leader branch might lead to a stronger electric field at the tip of the leader, as also noted by Celestin and Pasko (2011) and Skeltved et al. (2017). In the present simulations, the static vacuum solution is obtained through the method of moments (e.g., see Celestin et al., 2015) and runaway electrons are only injected at the location where the electric field magnitude gets below $50 \mathrm{kV} \cdot \mathrm{cm}^{-1}$.

Skeltved et al. (2017) also pointed out that the acceleration of runaway electrons under such constraints could not explain TGFs with the highest photon energy observed. However, it must be noted that under the $50 \mathrm{kV} \cdot \mathrm{cm}^{-1}$ field limitation hypothesis, a great 
deal of the potential drop is artificially made unavailable to the electrons in the simulations. In reality, the leader system is dynamic and as the field is screened by the production of streamers, the potential drop does not simply disappear but should be dynamically displaced and participate to the acceleration of runaway electrons.

An important point is to estimate the initial number of electrons at the source, in order to correctly scale the simulation. Indeed, the simulation is composed of 40000 electrons at the beginning and is scaled to the real number of electron at the source in a second step. The average bremsstrahlung photon production frequency per electron $\left\langle\nu_{\gamma}\right\rangle$, for electrons with energies greater than $\varepsilon_{\min }$ at each moment of time is (e.g., Celestin et al., 2015):

$$
<\nu_{\gamma}>(t)=N \int_{\varepsilon_{\text {min }}}^{+\infty} f(\varepsilon, t) \sigma_{\gamma}(\varepsilon) v_{e}(\varepsilon) d \varepsilon
$$

where $\sigma_{\gamma}(\varepsilon)=\int_{\varepsilon_{\min }}^{\varepsilon} \frac{d \sigma_{\gamma}}{d \varepsilon_{\gamma}}\left(\varepsilon, \varepsilon_{\gamma}\right) d \varepsilon_{\gamma}$ is the total cross section for production of bremsstrahlung photons with energies greater than $\varepsilon_{\min }$ by deflections of an electron with energy $\varepsilon>$ $\varepsilon_{\min }, N$ is the local air density, $f(\varepsilon, t)$ is the instantaneous normalized energy distribution of electrons at any moment of time, and $v_{e}(\varepsilon)=c \sqrt{1-\left(1+\frac{\varepsilon}{m c^{2}}\right)^{-2}}$ is the relativistic speed of an electron with energy $\varepsilon$ and rest mass $m$, and $c$ is the speed of light in vacuum. The total number of produced photons with energy greater than $\varepsilon_{\min }$ is (Celestin et al., 2015):

$$
N_{\gamma}=\int_{0}^{+\infty} N_{e}(t)<\nu_{\gamma}>(t) d t
$$

where $N_{e}(t)$ is the number of high-energy electrons as a function of the time. 


\subsection{Leader injection accompanied with RREAs in a homogeneous field}

For this section, we assume that the electron source is thermal runaway electrons produced by streamers and accelerated in a leader tip. They are accelerated further and a RREA takes place in the homogeneous ambient electric field $E_{0}>E_{t h}$ over a distance of $1 \mathrm{~km}$. This leader injection does not constrain the model to have a very localized electron source as the thermal runaway electrons propagate in a divergent field, possibly produced by different leader branches, and thus according to simulations, the electron source diameter can take values up to hundreds of meters. This is the reason why we estimate electron doses for this model with an initial source diameter between 0 and $2 \mathrm{~km}$ (as seen on Figure 5).

The initial number of electrons composing the electron source discussed above is defined so as to produce $10^{18}$ photons with energies $>1 \mathrm{MeV}$ in the end. It depends on the electric field, the length of the avalanche region, and the altitude. Using the average RREA speed 0.89c (Coleman \& Dwyer, 2006), the number of electron during a RREA is expressed as:

$$
N_{e}(t)=N_{0} \exp \left(\frac{z}{\lambda(E)}\right)=N_{0} \exp \left(\frac{t \times 0.89 c}{\lambda(E)}\right)
$$

Coleman and Dwyer (2006) expressed the avalanche length, also called e-folding length, for an electric field magnitude $E$ greater than $300 \mathrm{kV} \cdot \mathrm{m}^{-1}$ as a function of the electric field value as:

$$
\lambda(E)=\frac{7300 \pm 60 \mathrm{kV}}{\left(E-276 \pm 4 \mathrm{kV} \cdot \mathrm{m}^{-1}\right)}
$$

Taking a RREA spectrum as $f(\varepsilon) \propto \exp (-\varepsilon / 7.3 \mathrm{MeV})$, in equations (3) and (4), we can calculate the number of electrons at the beginning and at each moment of time during the avalanche, depending on the electric field value. In order to study the changes implied by different electric field strengths, we use two magnitudes: $400 \mathrm{~N} / N_{0} \mathrm{kV} \cdot \mathrm{m}^{-1}$ and $500 \mathrm{~N} / N_{0} \mathrm{kV} \cdot \mathrm{m}^{-1}$, where $N$ is the local air density and $N_{0}$ the air density at ground level. These two amplitudes respectively correspond to ratios $\xi=E / E_{t h}$ of $\sim 1.4$ and $\sim 1.8$.

The maximum electric field magnitude used in the present study is $500 \mathrm{~N} / N_{0} \mathrm{kV} \cdot \mathrm{m}^{-1}$ over a maximum length of the acceleration region of $1 \mathrm{~km}$. The injection of runaway electrons is localized at an altitude of $12 \mathrm{~km}$. The local electric field magnitude is therefore $118 \mathrm{kV} \cdot \mathrm{m}^{-1}$. Dwyer (2003), Figure 3 presents a figure showing the relativistic feedback threshold electric field magnitude as a function of the acceleration length at ground level. 
Using GEANT4, Skeltved et al. (2014), Figure 6 found somewhat lower thresholds, while in good general agreement with Dwyer (2003). Both results presented by Dwyer (2003) and Skeltved et al. (2014) are shown considering ground-level atmospheric density. At $12 \mathrm{~km}$ altitude, an acceleration under a field of $118 \mathrm{kV} \cdot \mathrm{m}^{-1}$ over $1 \mathrm{~km}$ is scalable to an acceleration under $500 \mathrm{kV} \cdot \mathrm{m}^{-1}$ over a length of $236 \mathrm{~m}$. Both figures presented by Dwyer (2003) and Skeltved et al. (2014), clearly show that the studied configuration is subcritical ("semi-stable", in the words of Dwyer (2003), although close to triggering relativistic feedback. Another equivalent way to observe the same fact is to use the figure 11 of Skeltved et al. (2014) showing the relativistic feedback electric field threshold as a function of the electric potential drop in the acceleration region. The total potential drop in our configuration is 118 MV. Analysis of Figure 11 of Skeltved et al. (2014) show that the maximum field magnitude for which relativistic feedback is not triggered somewhat exceeds $500 \mathrm{kV} \cdot \mathrm{m}^{-1}$ (for a field scaled to ground-level). In conclusion, relativistic feedback is not expected to occur in the configurations studied in the present paper.

To calculate the ambient dose equivalent, we need to estimate the electron fluence. However, the electron beam diameter remains a degree of freedom. We choose to estimate the dose depending on the electron beam diameter at the end of the avalanche, for diameters between 0 and $2 \mathrm{~km}$.

To estimate the electron beam diameter during the avalanche, we make the assumption that the beam radius follows a diffusion radius $r_{D}=\sqrt{\frac{\alpha D_{\perp}}{v} z(t)+R_{0}^{2}}$, where $R_{0}$ is the initial radius, taking $\alpha=1 / 4$ according to Monte Carlo simulations (Berge et al., 2019). For the diffusion coefficient $D_{\perp}$, we make use of the following estimate (Dwyer, 2010):

$$
D_{\perp} / v=\left(5.86 \cdot 10^{4}\right) E^{-1.79}
$$

in meters, where $E$ is the electric field expressed in units of $\mathrm{kV} \cdot \mathrm{m}^{-1}$.

\subsection{Photons and secondary electrons}

Additionally to doses from runaway electrons in the TGF source region, doses due to photons and due to electrons produced as a result of photon TGF collisions with air molecules are also estimated in the present study. We have used a Monte Carlo code based on Østgaard et al. (2008) to propagate photons in the atmosphere. The code takes into account three types of collisions for the photons. Photoelectric absorption is the main 
process for energies up to $\sim 30 \mathrm{keV}$, Compton scattering is the main process for energies from $\sim 30 \mathrm{keV}$ up to $\sim 30 \mathrm{MeV}$, and electron-positron pair production is the main process for energies higher than $\sim 30 \mathrm{MeV}$. Energy and position of secondary electrons created by all the above-mentioned processes are recorded for the most dangerous location, that is for the closest point along the axis of the source, within a 500-meter radius, $1 \mathrm{~km}$ above the source.

In order to focus on the worst case scenario, we simulated a point photon source at an altitude of $12 \mathrm{~km}$, for the sake of consistency with calculations of runaway electron doses. The initial velocities of the photons are uniformly distributed within a cone of $45^{\circ}$ opening half-angle and the scale height is $8.2 \mathrm{~km}$ (the scale height characterizes a planetary atmosphere; it is the increase in altitude corresponding to a decrease in atmospheric pressure by a factor $e$ ). The energy distribution is in agreement with the RREA phenomenon, which produces a $7.3 \mathrm{MeV}$ cut-off in the primary electron spectrum. Positrons created through electron-positron pair production are assumed to annihilate locally where the collision occurs, producing two photons with energy of $511 \mathrm{keV}$ in opposite direction that are taken into account in the simulation. Bremsstrahlung from secondary electrons produced by photon collisions is not taken into account. Again, $10^{18}$ initial photons are considered to be produced.

\section{Results}

Three levels of exposure are plotted in the figures presented in this paper in order to give an idea of the exposure compared to usual annual effective doses for workers: 1 $\mathrm{mSv}, 6 \mathrm{mSv}$, and $20 \mathrm{mSv}$. According to French law, workers receiving an annual cumulated effective dose above $1 \mathrm{mSv}$ are considered as exposed workers and therefore their exposure has to be assessed. For exposed workers, a management threshold is fixed at $6 \mathrm{mSv}$, defining two worker categories referred to as A and B. Category A workers potentially receive effective doses above $6 \mathrm{mSv}$ and have reinforced medical follow-ups. Category B workers potentially receive an effective dose $>1 \mathrm{mSv}$. However, for aircrews, the only annual regulatory limit is $20 \mathrm{mSv}$. In some figures, the 1-Sv limit is plotted, corresponding to a highly dangerous dose implying acute health effects, including nausea as an example. Neither limit takes natural and medical exposures into account. 
Although regulatory limits are established using effective doses, over the energy range considered in the present study, ambient dose equivalents $H^{*}(10)$ and effective doses have comparable values (see Figure 2).

\subsection{Pure leader model}

Using $f(\varepsilon, t)$ and $N_{e}(t)$ from our Monte Carlo simulations, $\frac{d \sigma_{\gamma}}{d \varepsilon_{\gamma}}$ from (Lehtinen, 2000) and assuming that a typical TGF observed from space produces $10^{18}$ photons, given the assumptions made about the potential drop (see Section 2.2), we found that $10^{14}$ runaway electrons need to be produced at the source (i.e., thermal runaway seeds with energy $>3.5 \mathrm{keV}$ injected in the vicinity of the leader tip, see (Celestin \& Pasko, 2011)) (calculated in Section 2.2). This number will be used for the number of initial runaway electrons hereafter.

Figure 3 shows the electron dose produced for one TGF in less than $1 \mathrm{~ms}$, obtained within the pure leader model in a 2-D cross-sectional view: depending on the altitude inside the avalanche and on the radial distance. The position of the leader tip (at an altitude of $12 \mathrm{~km}$ ) is shown as a red diamond.

Electrons propagate until they slow down in low-field regions. In this case, the RREA takes place over almost 750 meters in altitude up from the source and about 600 meters in diameter for most of the electrons.

The maximum of the dose delivered by the RREA is $0.29 \mathrm{~Sv}, 50$ meters above the source. At this distance, $90 \%$ of the electrons are contained in a 15-meter diameter disk. The energy spectrum of the electrons contained in the 15-meter diameter disk, 50 meters above the source is shown on Figure 4. This figure presents an instantaneous spectrum obtained when the mean position of electrons reaches $z=50 \mathrm{~m}$. A sharp cutoff around $30 \mathrm{MeV}$ observed in the spectrum is explained by the fact that electrons could only gain that much energy from the injection point to the moment they reached $50 \mathrm{~m}$.

The altitude for which the $H^{*}(10)$ dose produced by the RREA during less than $1 \mathrm{~ms}$ goes below the limit effective dose defining the workers category A (6 mSv) is 430 meters above the source, and at this altitude $90 \%$ of the electrons are included in a 280 meter diameter disk. The altitude for which the dose goes below the regulatory annual 


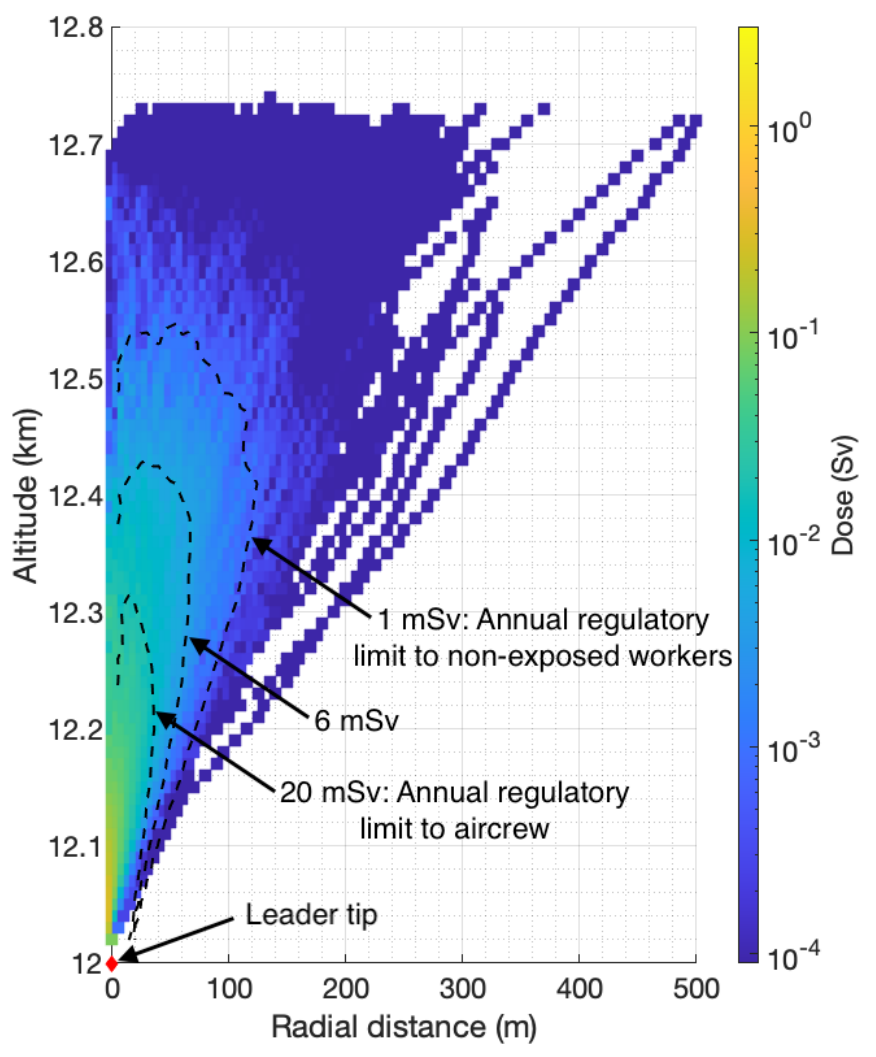

Figure 3. 2-D cross-sectional view of the calculated ambient dose equivalent associated with runaway electrons producing a TGF, obtained within pure leader model. The leader tip is represented as a red diamond. The dashed lines are isocontours at $1 \mathrm{mSv}, 6 \mathrm{mSv}$, and $20 \mathrm{mSv}$, presented here for comparison with the three levels of exposure corresponding to the annual regulatory limit to non-exposed workers $(1 \mathrm{mSv})$, the annual limit defining the category $\mathrm{A}$ of exposed workers $(6 \mathrm{mSv})$, and the annual regulatory limit to aircrew $(20 \mathrm{mSv})$. Although regulatory limits are established using effective doses, over the energy range considered in the present study, ambient dose equivalent $H^{*}(10)$ and effective doses have comparable values.

limit to the non-exposed workers $(1 \mathrm{mSv})$ is 550 meters above the source, and at this altitude $90 \%$ of the electrons are included in a 337-meter diameter disk.

\subsection{Leader injection accompanied with RREAs in a homogeneous field}

For an electric field of $400 \mathrm{kV} \cdot \mathrm{m}^{-1}$ normalized to ground level, a source altitude of $12 \mathrm{~km}$, and a length of the avalanche region of $1 \mathrm{~km}$, we found a number of $6 \cdot 10^{16}$ electrons is needed at the source so as to have $10^{18}$ photons with energy $>1 \mathrm{MeV}$ produced 


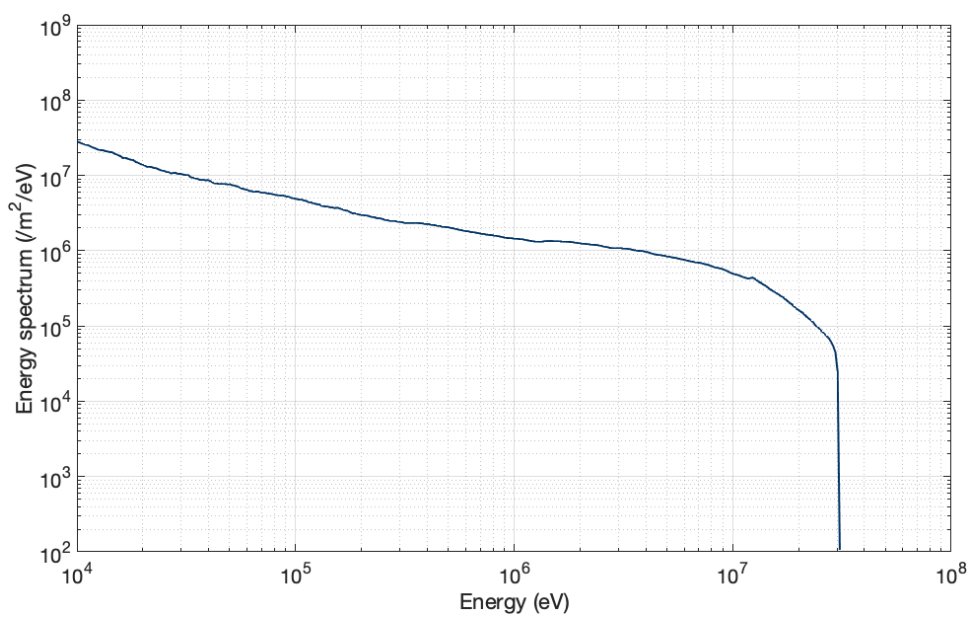

Figure 4. Energy spectrum of the RREA electrons contained in the 15-meter diameter disk, 50 meters above the source.

through bremsstrahlung (see Section 2.3). For an electric field of $500 \mathrm{kV} \cdot \mathrm{m}^{-1}$ normalized to ground level, a source altitude of $12 \mathrm{~km}$, and a total acceleration length of $1 \mathrm{~km}$, we found a number of $4 \cdot 10^{15}$ electrons at the source (see Section 2.3).

The dose produced by the electrons for one TGF during less than $1 \mathrm{~ms}$ obtained with a homogeneous electric field model at a $12 \mathrm{~km}$ altitude are plotted in Figure 5, for two different electric field values: $400 \mathrm{kV} \cdot \mathrm{m}^{-1}$ (Figure $5 . \mathrm{A}$ ) and $500 \mathrm{kV} \cdot \mathrm{m}^{-1}$ (Figure $5 . \mathrm{B}$ ) (scaled to ground-level), respectively, both extending over a length of $1 \mathrm{~km}$. Panels A.1 and B.1 show the dose produced at the end of a 1-kilometer-long avalanche, at an altitude of $13 \mathrm{~km}$, as a function of the electron beam diameter. Panels A.2 and B.2 show the dose produced as a function of the electron beam diameter and as a function of the altitude inside the avalanche. Panels A.3 and B.3 show the dose as a function of the altitude inside the avalanche for a point source. A striped area indicates the non-physical cases, where the initial radius of the source would be imaginary for such small electron beam diameters at the end of the avalanche region, because of the diffusion process. A spatial 2-D representation of the point source case for electric field magnitudes of 400 $\mathrm{kV} \cdot \mathrm{m}^{-1}$ and $500 \mathrm{kV} \cdot \mathrm{m}^{-1}$ is presented in Figure 6.

The diffusion process explains also the non-linear horizontal axis for the source diameter, below the panels A.2 and B.2. We also consider that we need at least 2 avalanche lengths in order to have electrons following the RREA spectrum at the end of the avalanche. 
Under this assumption, we found that at this altitude of $12 \mathrm{~km}$, with an avalanche over $1 \mathrm{~km}$, electric fields below $340 \mathrm{kV} \cdot \mathrm{m}^{-1}$ at ground level are not sufficient to get electrons following a RREA spectrum.

One major result of this study is that the ambient dose equivalent can reach high values, above regulatory annual limits for aircrew $(20 \mathrm{mSv})$ even for large electron beam diameter. For low electric fields $\left(340 \mathrm{kV} \cdot \mathrm{m}^{-1}\right)$, we found that all along the electron beam the dose is higher that $20 \mathrm{mSv}$ for source diameter up to $650 \mathrm{~m}$, and the dose at the end of the avalanche is higher than $1 \mathrm{~Sv}$ for source diameters up to $200 \mathrm{~m}$. In Figure 5.A, the ambient dose equivalent at the end of the avalanche has a minimum of $30 \mathrm{mSv}$ for the largest beam diameter of $2 \mathrm{~km}$, and it exceeds an extremely high dose of $1 \mathrm{~Sv}$, reaching $7 \mathrm{~Sv}$, for the smaller final beam diameter of $130 \mathrm{~m}$. Along the avalanche, the dose does not fall below $1 \mathrm{~Sv}$ for a point source, and $0.5 \mathrm{mSv}$ for a final beam diameter of 2 $\mathrm{km}$.

In Figure 5.B, the ambient dose equivalent at the end of the avalanche has a minimum of $54 \mathrm{mSv}$ for the largest beam diameter of $2 \mathrm{~km}$, and it reaches even higher values than for the case at $400 \mathrm{kV} \cdot \mathrm{m}^{-1}$ (Figure 5.A), with $18 \mathrm{~Sv}$ for the smallest final beam diameter of 107 meters. Along the avalanche, the dose does not fall below $0.3 \mathrm{~Sv}$ for a point source, and $40 \mu \mathrm{Sv}$ for a final beam diameter of $2 \mathrm{~km}$.

For a point source, the dose is extremely high at the very beginning, reaching values of hundreds of sieverts. This is artificial, due to the fact that the number of electrons per unit area is very large, and happens only over 20 meters above the point source.

Concerning the electric field value, comparing Figures 5 and 6 , we can say that the greater the electric field, the greater is the dose at the end of the avalanche. The bremsstrahlung photon production frequency per electron $\nu_{\gamma}$ does not depend on the electric field, but there is a different number of electrons at each moment of time depending on the electric field (through $\lambda(E)$ ). For a given number of initial electrons, the number of electrons at the end of the avalanche is greater for greater electric fields. Thus, during the avalanche, on average, the number of electrons needs to be lower for greater electric field to maintain the number of TGF photons to $10^{18}$. It is possible to see this effect on the number of initial electrons that is $6 \cdot 10^{16}$ electrons for $\mathrm{E}=400 \mathrm{kV} \cdot \mathrm{m}^{-1}$, and only $4.1 \cdot 10^{15}$ electrons for $\mathrm{E}=\mathrm{kV} \cdot \mathrm{m}^{-1}$. 


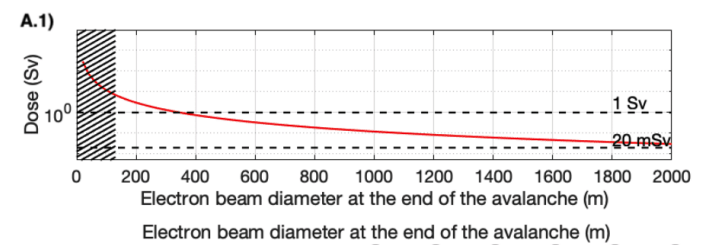

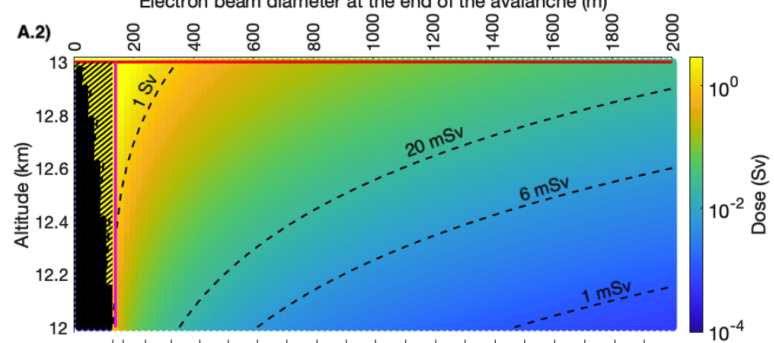

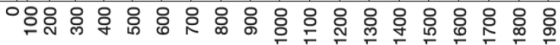

Source diameter $(\mathrm{m})$
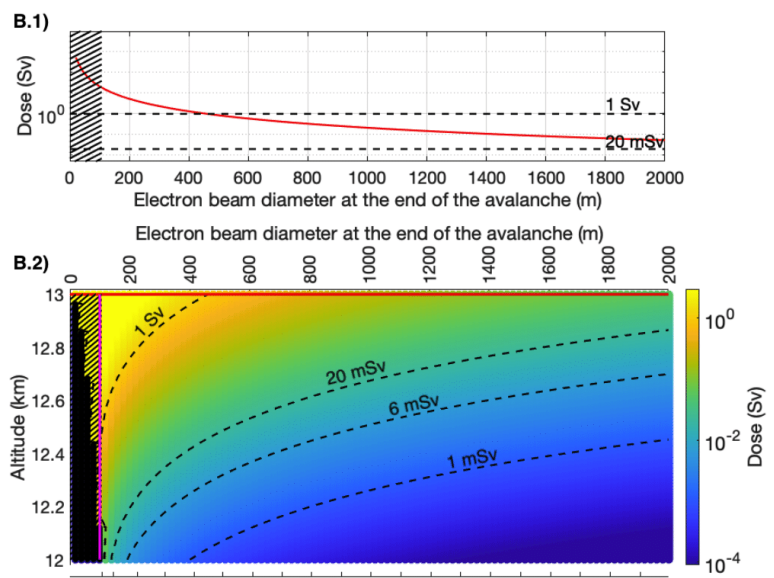

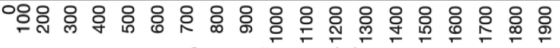

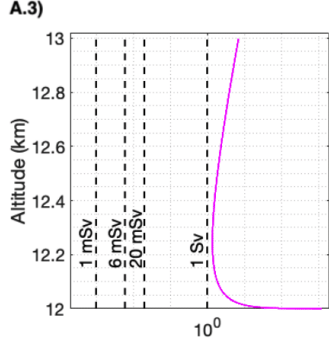

Dose (Sv)

\section{$\mathrm{E}=500 \mathrm{kV} / \mathrm{m}$ at ground level}

B.3)

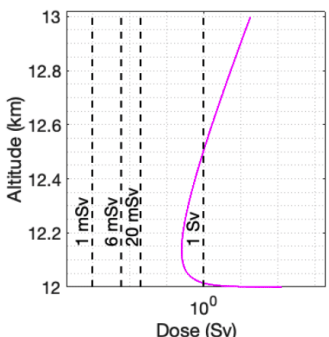

Figure 5. Representation of the calculated ambient dose equivalent for electrons, within a homogeneous electric field model. The electric field value corresponds to: (A) $400 \mathrm{kV} \cdot \mathrm{m}^{-1}$ and (B) $500 \mathrm{kV} \cdot \mathrm{m}^{-1}$ at ground level. The dashed lines represent $H^{*}(10)$ isocontours. (Panels A.1 and B.1) Dose produced at the end of a 1-kilometer avalanche, at an altitude of $13 \mathrm{~km}$, as a function of the electron beam diameter at the end of the avalanche. (Panels A.2 and B.2) Dose produced inside the avalanche as a function of the electron beam diameter at the end of the avalanche for various altitudes. The black and striped area represent a non-physical situation considering the minimum diffusion diameter of a point source. (Panels A.3 and B.3) Dose as a function of the altitude inside the avalanche for a point source that ends with: (A) a 130 meter diameter and (B) a 107-meter diameter, represented with a magenta line in panels (2). The avalanche length $\lambda$ and the initial number of runaway electrons $N_{0}$ are respectively: (A) 249 meters and $6 \cdot 10^{16}$ electrons, and (B) 138 meters and $4.1 \cdot 10^{15}$ electrons. 

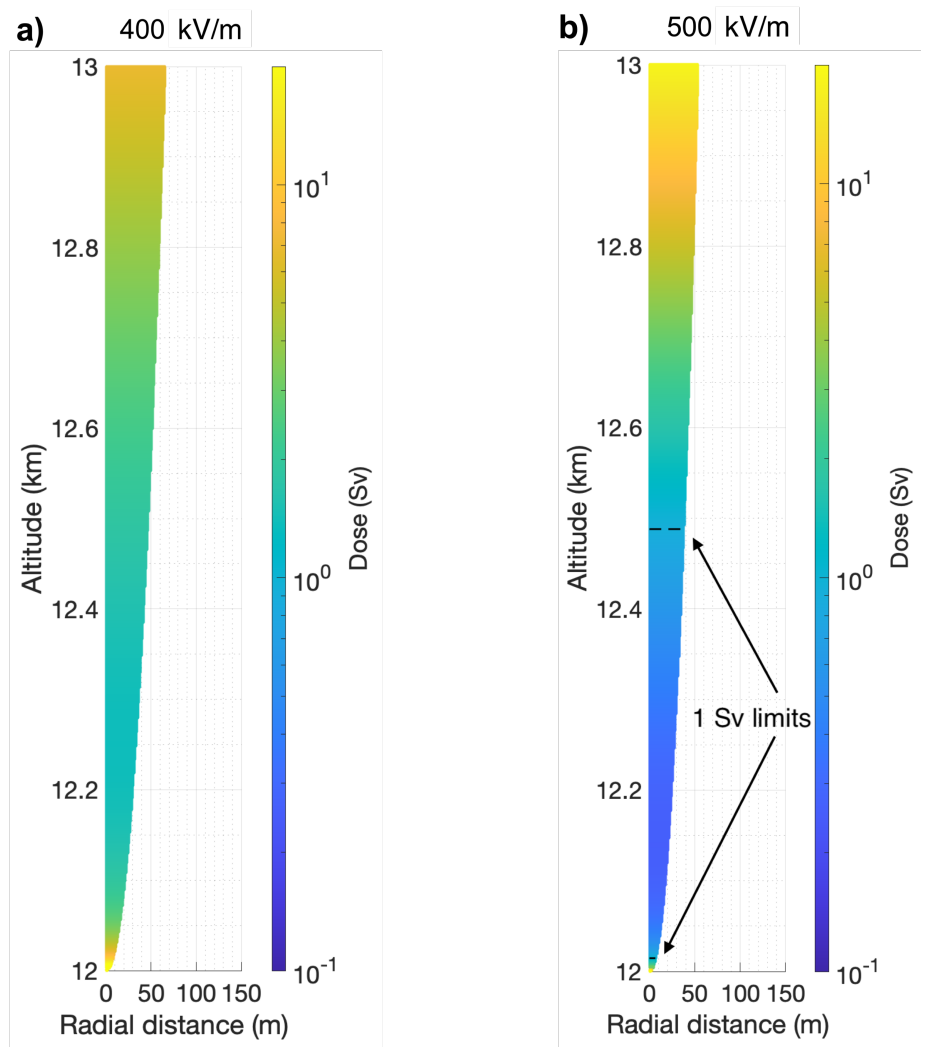

Figure 6. 2-D representation of the calculated ambient dose equivalent for runaway electrons further accelerated in a homogeneous electric field region, assuming a point source. (a) The electric field value is $400 \mathrm{kV} \cdot \mathrm{m}^{-1}$ at ground level. The minimum dose reached is $1.4 \mathrm{~Sv}$. The dose at the end of the avalanche region is $7 \mathrm{~Sv}$. (b) The electric field value is $500 \mathrm{kV} \cdot \mathrm{m}^{-1}$ at ground level. The minimum dose reached is $0.3 \mathrm{~Sv}$. The dose at the end of the avalanche region is $18 \mathrm{~Sv}$. The colorbar is the same for both plots and goes from $0.1 \mathrm{~Sv}$ to $20 \mathrm{~Sv}$.

\subsection{Photons and secondary electrons}

The ambient dose equivalent from photons is plotted in Figure 7. The dose between the source and about $1 \mathrm{~km}$ above is not calculated here, as shown in Figure 1, because photons are produced by electrons, that propagate from the source over at least $700 \mathrm{~m}$ in both models used in this paper. In this region, the dose is dominated by runaway electrons. Photons are collected in different rings, in order to estimate the fluence as a function of the radial distance, until they reach either an upper virtual screen at $500 \mathrm{~km}$ or the ground (Figure 1). This ring-based method associated with a Monte Carlo code creates a lack of resolution along the axis of symmetry, some kilometers above the source 


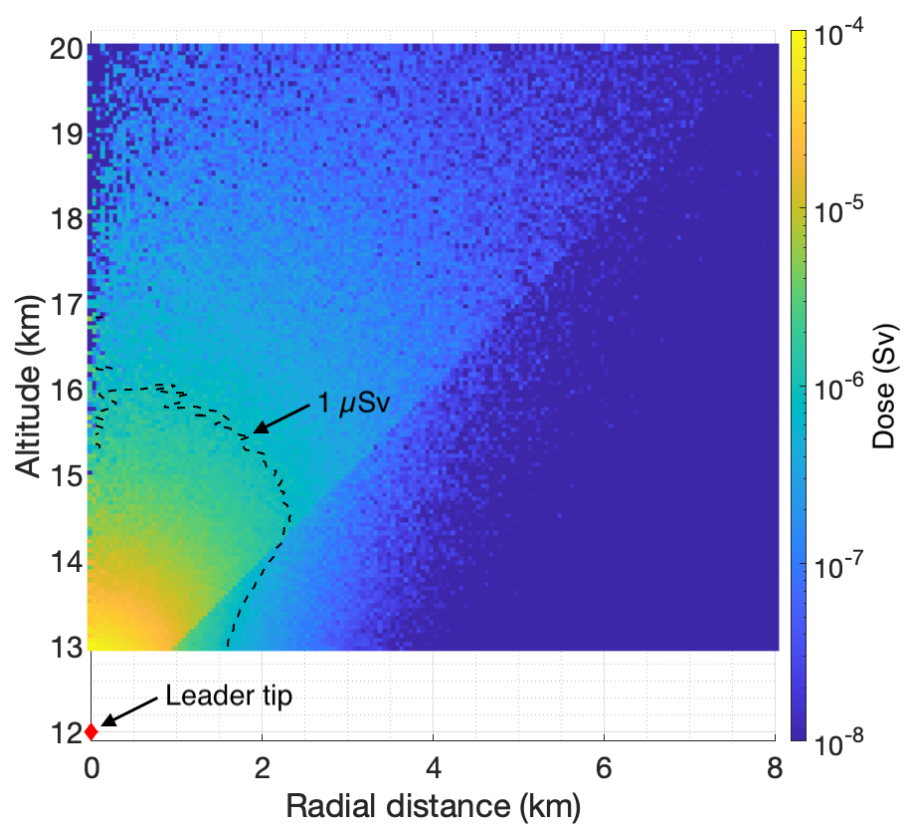

Figure 7. Ambient doses equivalent generated by photons as a function of the observation altitude and the radial distance. The red diamond is the position of the source of photons, situated at 12 kilometers of altitude. The maximum dose is reached at the closest point to the source region and reaches $90 \mu \mathrm{Sv}$.

(also noticeable in Figure 3 for the runaway electron Monte Carlo code) ; this is a purely numerical effect, due to a weak probability to have particles in the smallest rings, and it should not be concluded that the dose is weaker close to the axis.

The step in the dose along the $45^{\circ}$ line from the source is due to the initial momentum distribution of the photons. The three safety limits used in the present work are not plotted here because photon doses are all under these limits, but we plotted the $1 \mu \mathrm{Sv}$ contour for reference. The maximum of the dose is found closest to the source, i.e., $1 \mathrm{~km}$ above the source, and reaches $90 \mu \mathrm{Sv}$. It is clear from this simulation, that the dose between the source and $1 \mathrm{~km}$ above is higher, and could be very high but this is only due to the fact that we chose a point source for the photons. The extent of the highest doses obtained (above $1 \mu \mathrm{Sv}$ ) are contained in an area of $4 \mathrm{~km}$ in altitude and a maximum of $4 \mathrm{~km}$ in diameter.

Concerning secondary electrons, we found that a maximum of $0.6 \mu \mathrm{Sv}$ would be delivered one kilometer above the source. 
Bottollier-Depois et al. (2000) measured an average flight dose rate for a Paris-Tokyo flight of $6 \mu \mathrm{Sv} \cdot \mathrm{h}^{-1}$. To give an idea of the impact of these doses over a total flight dose, assuming this mean dose rate of $6 \mu \mathrm{Sv} \cdot \mathrm{h}^{-1}$ for a 10 hour-flight, the dose received from photons of one TGF at the worst location would represent an increase of $150 \%$ of the total flight dose. The dose received from secondary electrons of one TGF would represent only an increase of $1 \%$ of the total flight dose. Even though the extent could be even larger than for photons, secondary electrons produce doses so small that, to see an impact on the calculation of the total dose received from flights, aircrews should find themselves in the vicinity of a TGF several tens of times a year.

\section{Discussion}

\subsection{Calculated doses}

Ambient dose equivalents produced by electron avalanches are much larger than photon and secondary electron doses. Therefore, runaway electron doses are the most concerning here, at least approaching the very high dose of $1 \mathrm{~Sv}$ in both models studied in the present paper. Comparing the extent of the areas where doses are delivered, as photons propagate further in the atmosphere, one needs to consider a larger region of space for the photon dose (about 5-km wide over almost 10-km long), but associated with relatively small doses, between $0.1 \mu \mathrm{Sv}$ to $0.1 \mathrm{mSv}$. The region of interest for electrons is on the order of one kilometer long and 400-meters wide (leader model) to some kilometers wide (homogeneous field model), but corresponding to very high doses $(>20$ $\mathrm{mSv})$.

The two models used here do not give the same results. The pure leader model implies a high dose in the first third of the avalanche, mostly due to the very small radial extent close to the leader tip, even though the maximum number of electrons occurs at $\sim 320 \mathrm{~m}$ from the source point. On the contrary, the homogeneous field model implies a farther maximum dose, which precisely occurs at the end of the avalanche, chosen here as 1-km long (except when considering a point source case ; for this particular case, the dose can also reach very high values at the very beginning of the avalanche, a small extent implying a very high density).

We can also compare these results with those of Dwyer et al. (2010). Their work is comparable to the homogeneous field situation studied in this paper, but uses effec- 
tive doses in antero-posterior direction unlike the ambient dose equivalent that we use here (see Figure 2 for the comparison). They estimated a TGF dose at the end of the avalanche as a function of the electron beam diameter ; our results are similar to the TGF doses that they calculated, taking into account that ambient dose equivalent conversion coefficients are greater than effective dose conversion coefficients for energies around 1 $\mathrm{MeV}$ (see Figure 2). Actually, we found the same results as Dwyer et al. (2010) with effective doses, and have now an estimation of the dose all along the avalanche region.

For the homogeneous model, the variation of the dose along the avalanche depends on the parameters of the problem: electric field value, length of the avalanche, and source altitude. The higher the electric field, the higher the dose at the end of the avalanche. However, the dose along the avalanche is lower, due to the lower number of initial electrons, as it can be seen in Figures 5 and 6 . Concerning the influence of the altitude, the higher the altitude, the lower the dose at the end of the avalanche (e.g., doses at the end of the avalanche for a point source: $12 \mathrm{~Sv}$ for $10 \mathrm{~km}$; $7 \mathrm{~Sv}$ for $12 \mathrm{~km}$ ), but with a greater dose along the avalanche. Finally, we found that longer avalanches imply lower doses along the whole avalanche. This can be easily understood by the fact that since we fix the number of photons produced during the TGF, for longer avalanches, electrons are less compactly packed than for shorter avalanches. For avalanches shorter than $1 \mathrm{~km}$ (e.g., 500 meters), the dose reaches around $1 \mathrm{~Sv}$ all along the avalanche.

These results, especially for the homogeneous field model, were obtained for a very specific case designed to fit our current knowledge of TGFs: source altitude of $12 \mathrm{~km}$, ambient electric field value of $400 \mathrm{or} 500 \mathrm{kV} \cdot \mathrm{m}^{-1}$, and the length of the avalanche region of $1 \mathrm{~km}$. However, while studying the impact of these parameters, we observed that even for low electric field values $\left(340 \mathrm{kV} \cdot \mathrm{m}^{-1}\right)$, lower altitudes $(10 \mathrm{~km})$, or longer avalanche regions, electron doses were still approaching the 1-Sv-value at the end of the avalanche. Concerning the pure leader model, the results depend on the initial number of electrons, and vary proportionally with it.

\subsection{TGF brightness assumption}

For both models, we chose a fixed value of $10^{18}$ photons produced at the source of the TGF (called "TGF brightness" in the following), which is in agreement with satellite measurements (e. g., Mailyan et al., 2019). However, the maximum possible bright- 
ness of TGFs is still an open question. For instance, Gjesteland et al. (2015) have shown a diversity in the intrinsic brightness of TGFs going up to $10^{20}$ of photons with energies $>1 \mathrm{MeV}$. Thus, one cannot exclude TGF brightness up to $10^{20}$, knowing that all the detectors in space suffered saturation for some TGF events, and that Mailyan et al. (2016, 2019); Sarria et al. (2019); Gjesteland et al. (2015) reported such high values. Of course, TGFs with brightness up to $10^{20}$ are probably much rarer events, but knowing that the dose depends linearly on the TGF brightness, in principle the associated dose might be 100 times greater for brightness up to $10^{20}$. Thus, especially for doses associated with photons discussed in this paper, one would obtain significant values, reaching up to 9 $\mathrm{mSv}$, and resulting in 1-km wide areas with levels of radiation exceeding the 1-mSv safety limit.

\subsection{Effect of the aircraft cabin}

In order to estimate what will be the influence of runaway electrons on crew doses, we make the following considerations. On actual airplanes the aluminum skin is about $1.6 \mathrm{~mm}$. For the A320 airplane for instance, it goes from $0.8 \mathrm{~mm}$ where it is not pressurized, up to $7 \mathrm{~mm}$ at the door frames (Rappeneau, K., Air France, personal communication, June 29, 2020). In this work we choose to model aircraft cabins assuming a 5mm aluminum skin, to account for a margin that may include the fact that TGFs are mostly upward, and there are the floor and the luggages below the passengers and crews that could attenuate the radiation.

Electron stopping power value for aluminum in the minimum ionizing range corresponds to $4 \mathrm{MeV} \cdot \mathrm{cm}^{-1}$ (Berger et al., 2005). Therefore, the electron spectrum (Figure 4) shifts by about $2 \mathrm{MeV}$ to lower energies. The impact on the doses are shown for electrons in Figure 8. The dose is slightly attenuated by the cabin, but the difference represents around $30 \%$ of its value. One can add that secondary particles will be produced by electrons penetrating the cabin, scattering from many directions. Aircraft passengers will be therefore exposed from a larger solid angle. Secondary particles produced by electron penetrating the cabin would include bremsstrahlung photons, that would have negligible effects compared to the extremely high doses delivered by electrons here, but will also include neutrons, that have the highest weighting factors concerning equivalent dose calculations. No simulation to determine doses delivered by these neutrons has been run in this work, but one can note that neutrons have been studied in (Tavani et al., 2013) 

by $80 \%$, reaching only $0.1 \mu \mathrm{Sv}$.

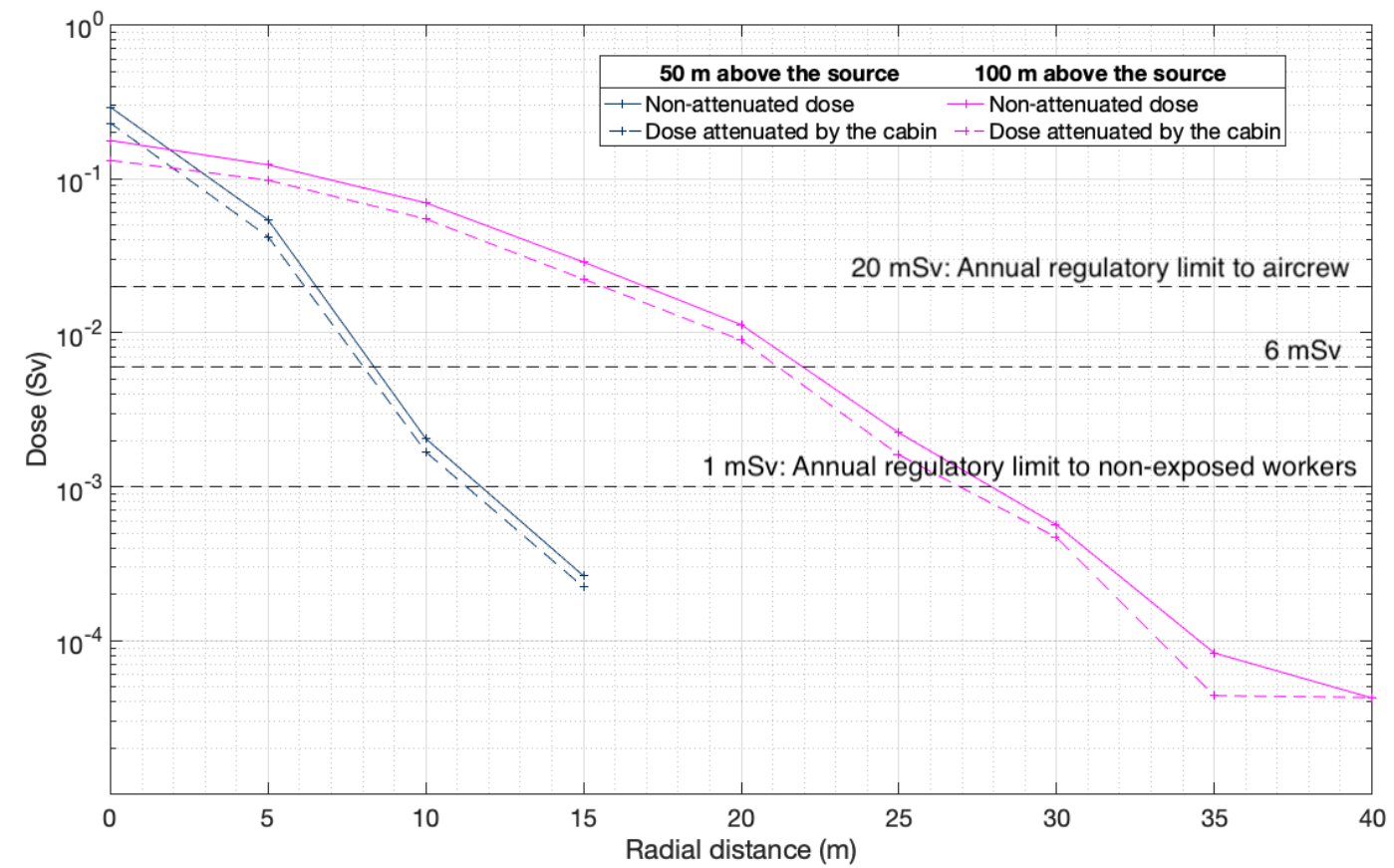

Figure 8. Attenuation of the electron dose by the cabin within the pure leader model, with the observation $50 \mathrm{~m}$ above the source (blue) and $100 \mathrm{~m}$ above the source (magenta). The calculation is made by subtracting $2 \mathrm{MeV}$ from each electron. Electrons with energies lower than 2 $\mathrm{MeV}$ are simply removed as they stop in the aircraft skin. 


\subsection{Radiation risk associated with TGFs}

A risk analysis of an event should take into account the likelihood of the event to happen and its severity. Even though it seems rather rare for an aircraft to find itself in a TGF source region, that is to say at the wrong place, at the wrong time, the consequences could be serious.

It is currently impossible to predict where and when a TGF will occur, and it is still difficult to predict the exact spatial and temporal distribution of TGFs around the world. In fact, more and more TGF are detected as specifically designed instruments are being used, especially fast instruments able to detect several TGF photons produced in about $100 \mu \mathrm{s}$, and that does not saturate with the TGF high-energy photons (up to 40 $\mathrm{MeV}$ ). Currently, the Atmosphere-Space Interactions Monitor (ASIM) on the International Space Station, launched in April 2018, is composed of the MXGS (Modular X-and Gamma-ray Sensor) instrument designed to detect TGFs, with a low energy detector and a high energy detector, to cover energies between $15 \mathrm{keV}$ and $20 \mathrm{MeV}$ (Neubert et al., 2019). ASIM will help to have a better appreciation on the spatial and temporal distribution of TGFs.

It seems difficult today to quantify precisely the probability for an aircraft to find itself in a TGF and so to predict the dose that would be received statistically. This work calls for a need to run a thorough radiation risk assessment for aircraft passengers flying in thunderstorms, including an estimation of the probability for an aircraft to find itself in a TGF source region.

It is worth mentioning that ongoing statistical studies based on data collected using passive dosimeters on board Air France flights have not found significant dose increases associated with routes crossing thunderstorms (lower than a few mSv over 3-month integration periods) (Trompier et al., 2014).

\section{Conclusions}

In the present work, radiation dose calculations associated with TGF events are carried out within two production models. Monte Carlo simulations for photons, secondary electrons, and runaway electrons within a "pure" leader model, or their further acceleration in a hypothetical homogeneous field, show that: 
- Secondary electrons produce negligible doses (a fraction of microsievert)

- Photons produce doses of a fraction of millisievert $(<1 \mathrm{mSv})$ over an area spanning over several kilometers

- Runaway electrons may produce very significant doses (approaching $1 \mathrm{~Sv}$ ) in compact volumes

This work hence shows that high-energy electrons causing TGFs are likely to correspond to high doses, although in compact regions: high doses on the one hand, and a low probability for an aircraft to lie in the electron beam on the other hand. In order to qualify the extremely high doses announced in this work, we note that none of the monitoring done with dosimeters on airplanes until now has measured doses as high as around $20 \mathrm{mSv}$ from TGFs, likely because pilots avoid thunderstorms in most cases. However, the need of a thorough radiation risk assessment for aircraft passengers and aircrews is clearly called by the present work. Further TGF-focused missions could contribute to answer these questions regarding radiation dose issues. Moreover, measurements done in thunderstorms will be necessary to confirm doses estimated in this work.

\section{Acknowledgments}

This work is supported by the French space agency (CNES) in the framework of the project OREO, the French Institute of Radiation Protection and Nuclear Safety (IRSN), and Air France. The Fluka database provides us conversion coefficients. We are grateful to Nini Berge (LPC2E, University of Orleans, CNRS) for her simulation results of secondary electrons produced by photons and the related discussions. Data allowing to reproduce the figures of this paper are available with https://doi.org/10.6084/m9.figshare.12958115.v2.

\section{References}

Albrechtsen, K. H., stgaard, N., Berge, N., \& Gjesteland, T. (2019). Observationally weak tgfs in the rhessi data. J. Geophys. Res., 124(1), 287-298. Retrieved from https://agupubs.onlinelibrary.wiley.com/doi/abs/10.1029/ 2018JD029272 doi: https://doi.org/10.1029/2018JD029272

Balanis, C. A. (1989). Advanced engineering electromagnetics. In (p. 670). John Wiley.

Bazelyan, E., \& Raizer, Y. (2000). Lightning physics and lightning protection. Taylor 
\& Francis.

Berge, N. L., Celestin, S., Xu, W., Marshall, R. A., \& Cummer, S. A. (2019). Constraining source properties using tgf-associated radio emissions. Meeting, San Francisco, CA, USA(AE44A-06).

Berger, M. J., Coursey, J. S., Zucker, M. A., \& Chang, J. (2005). Stopping-Power and Range Tables for Electrons, Protons, and Helium Ions. Natl. Instit. of Stand. and Technol..

Berger, M. J., Inokuti, M., Anderson, H. H., Bichsel, H., Dennis, J. A., Powers, D., ... Turner, J. E. (2016). Report 37. Journal of the International Commission on Radiation Units and Measurements, os19(2), NP-NP. doi: 10.1093/jicru/os19.2.Report37

Bottollier-Depois, J.-F., Chau, Q., Bouisset, P., Kerlau, G., Plawinski, L., \& Lebaron-Jacobs, L. (2000). Assessing exposure to cosmic radiation during long-haul flights. Radiation Research, 153(5), 526 - 532. doi: 10.1667/0033-7587(2000)153[0526:AETCRD]2.0.CO;2

Bottollier-Depois, J.-F., Beck, P., Latocha, M., Mares, V., Matthi, D., Rhm, W., \& Wissmann, F. (2012). Comparison of codes assessing radiation exposure of aircraft crew due to galactic cosmic (No. 173). Luxembourg. doi: 10.2768/22100

Bowers, G. S., Smith, D. M., Kelley, N. A., Martinez-McKinney, G. F., Cummer, S. A., Dwyer, J. R., ... Rassoul, H. K. (2018). A terrestrial gamma-ray flash inside the eyewall of hurricane patricia. J. Geophys. Res., 123(10), 4977-4987. doi: https://doi.org/10.1029/2017JD027771

Briggs, M. S., Fishman, G. J., Connaughton, V., Bhat, P. N., Paciesas, W. S., Preece, R. D., .. Chekhtman, A. (2010). First results on terrestrial gamma ray flashes from the Fermi Gamma-ray Burst Monitor. J. Geophys. Res., 115(A7), A07323. doi: 10.1029/2009JA015242

Briggs, M. S., Xiong, S., Connaughton, V., Tierney, D., Fitzpatrick, G., Foley, S., ... Hutchins, M. L. (2013). Terrestrial gamma-ray flashes in the Fermi era: Improved observations and analysis methods. J. Geophys. Res., 118(6), 38053830. doi: $10.1002 /$ jgra. 50205

Celestin, S., \& Pasko, V. P. (2010). Soft collisions in relativistic runaway electron avalanches. J. Phys. D: Appl. Phys., 43(31), 315206. doi: 10.1088/0022-3727/ $43 / 31 / 315206$ 
Celestin, S., \& Pasko, V. P. (2011). Energy and fluxes of thermal runaway electrons produced by exponential growth of streamers during the stepping of lightning leaders and in transient luminous events. J. Geophys. Res., 116, A03315. doi: 10.1029/2010JA016260

Celestin, S., Xu, W., \& Pasko, V. P. (2015). Variability in fluence and spectrum of high-energy photon bursts produced by lightning leaders. J. Geophys. Res., 120(12), 10,712-10,723. doi: 10.1002/2015JA021410

Clairand, I., Fuller, N., Bottollier-Depois, J.-F., \& Trompier, F. (2009). The sievert system for aircrew dosimetry. Radiation Protection Dosimetry(136 (4)).

Coleman, L. M., \& Dwyer, J. R. (2006). Propagation speed of runaway electron avalanches. Geophys. Res. Lett., 33(11), L11810. doi: 10.1029/2006GL025863

Cummer, S. A., Briggs, M. S., Dwyer, J. R., Xiong, S., Connaughton, V., Fishman, G. J., ... Solanki, R. (2014). The source altitude, electric current, and intrinsic brightness of terrestrial gamma ray flashes. Geophys. Res. Lett., 41(23), 8586-8593. doi: 10.1002/2014GL062196

Cummer, S. A., Lu, G., Briggs, M. S., Connaughton, V., Xiong, S., Fishman, G. J., \& Dwyer, J. R. (2011). The lightning-TGF relationship on microsecond timescales. Geophys. Res. Lett., 38(14), L14810. doi: 10.1029/2011GL048099

Cummer, S. A., Lyu, F., Briggs, M. S., Fitzpatrick, G., Roberts, O. J., \& Dwyer, J. R. (2015). Lightning leader altitude progression in terrestrial gamma-ray flashes. Geophys. Res. Lett., 42(18), 7792-7798. doi: 10.1002/2015GL065228

Dwyer, J. R. (2003). A fundamental limit on electric fields in air. Geophys. Res. Lett., 30(20), 2055. doi: 10.1029/2003GL017781

Dwyer, J. R. (2008). Source mechanisms of terrestrial gamma-ray flashes. J. Geophys. Res., 113(D10), D10103. doi: 10.1029/2007JD009248

Dwyer, J. R. (2010). Diffusion of relativistic runaway electrons and implications for lightning initiation. J. Geophys. Res., 115(3), A00E14. doi: 10.1029/2009JA014504

Dwyer, J. R., Smith, D. M., \& Cummer, S. A. (2012). High-Energy Atmospheric Physics: Terrestrial Gamma-Ray Flashes and Related Phenomena. Space Science Reviews, 173(1-4), 133-196. doi: 10.1007/s11214-012-9894-0

Dwyer, J. R., Smith, D. M., Uman, M. A., Saleh, Z., Grefenstette, B., Hazelton, B., \& Rassoul, H. K. (2010). Estimation of the fluence of high-energy electron 
bursts produced by thunderclouds and the resulting radiation doses received in aircraft. J. Geophys. Res., 115(D9). doi: 10.1029/2009JD012039

Fishman, G. J., Bhat, P. N., Mallozzi, R., Horack, J. M., Koshut, T., Kouveliotou, C., ... Paciesas, W. S. ～(1994). Discovery of Intense GammaRay Flashes of Atmospheric Origin. $\quad$ Science, 264(5163), 1313-1316. doi: 10.1126/science.264.5163.1313

Fishman, G. J., Briggs, M. S., Connaughton, V., Bhat, P. N., Paciesas, W. S., von Kienlin, A., ... Meegan, C. A. (2011). Temporal properties of the terrestrial gamma-ray flashes from the Gamma-Ray Burst Monitor on the Fermi Observatory. J. Geophys. Res., 116(A7), A07304. doi: 10.1029/2010JA016084

Gjesteland, T., stgaard, N., Laviola, S., Miglietta, M. M., Arnone, E., Marisaldi, M., ... Montanya, J. (2015). Observation of intrinsically bright terrestrial gamma ray flashes from the mediterranean basin. J. Geophys. Res., 120(23), 12,14312,156. Retrieved from https://agupubs.onlinelibrary.wiley.com/doi/ abs/10.1002/2015JD023704 doi: https://doi.org/10.1002/2015JD023704

Heumesser, M., Chanrion, O., Neubert, T., Christian, H., Dimitriadou, K., Gordillo-Vazquez, F. J., ... Khn, C. (2020). Spectral observations of optical emissions associated with terrestrial gamma-ray flashes. Geophys. Res. Lett., e2020GL090700. ～(e2020GL090700 2020GL090700) doi: https://doi.org/10.1029/2020GL090700

ICRP. (2007). The 2007 recommendations of the international commission on radiological protection (No. ICRP Publication 103).

Khn, C., Diniz, G., \& Harakeh, M. N. (2017). Production mechanisms of leptons, photons, and hadrons and their possible feedback close to lightning leaders. Journal of Geophysical Research: Atmospheres, 122(2), 1365-1383. doi: https://doi.org/10.1002/2016JD025445

Khn, C., Heumesser, M., Chanrion, O., Nishikawa, K., Reglero, V., \& Neubert, T. (2020). The emission of terrestrial gamma ray flashes from encountering streamer coronae associated to the breakdown of lightning leaders. Geophys. Res. Lett., 47(20), e2020GL089749. Retrieved from https:// agupubs .onlinelibrary ·wiley.com/doi/abs/10.1029/2020GL089749 (e2020GL089749 10.1029/2020GL089749)～doi: https://doi.org/10.1029/ 2020GL089749 
Kim, Y.-K., Santos, J. P., \& Parente, F. (2000). Extension of the binary-encounterdipole model to relativistic incident electrons. Phys. Rev. A, 62(5), 052710. doi: 10.1103/PhysRevA.62.052710

Lehtinen, N. G. (2000). Relativistic runaway electrons above thunderstorms (Unpublished doctoral dissertation). STANFORD UNIVERSITY.

Liu, N., \& Dwyer, J. R. (2013). Modeling terrestrial gamma ray flashes produced by relativistic feedback discharges. $\quad J$. Geophys. Res., 118(5), 2359-2376. Retrieved from https://agupubs.onlinelibrary.wiley.com/doi/abs/ 10.1002/jgra.50232 doi: https://doi.org/10.1002/jgra.50232

Lu, G., Blakeslee, R. J., Li, J., Smith, D. M., Shao, X.-M., McCaul, E. W., ... Cummer, S. A. (2010). Lightning mapping observation of a terrestrial gammaray flash. Geophys. Res. Lett., 37(11), L11806. doi: 10.1029/2010GL043494

Mailyan, B. G., Briggs, M. S., Cramer, E. S., Fitzpatrick, G., Roberts, O. J., Stanbro, M., ... Dwyer, J. R. (2016). The spectroscopy of individual terrestrial gamma-ray flashes: Constraining the source properties.

J. Geophys. Res., 121(11), 11,346-11,363. Retrieved from https:// agupubs.onlinelibrary.wiley.com/doi/abs/10.1002/2016JA022702 doi: https://doi.org/10.1002/2016JA022702

Mailyan, B. G., Xu, W., Celestin, S., Briggs, M. S., Dwyer, J. R., Cramer, E. S., ... Stanbro, M. (2019). Analysis of individual terrestrial gamma-ray flashes with lightning leader models and fermi gamma-ray burst monitor data. J. Geophys. Res., 124(8), 7170-7183. doi: 10.1029/2019JA026912

Marisaldi, M., Smith, D. M., Brandt, S., Briggs, M. S., Budtz-Jørgensen, C., Campana, R., ... Cummer, S. A. (2015). High-energy radiation from thunderstorms and lightning with LOFT. arXiv e-prints.

Marisaldi, M., Tavani, M., Argan, A., Trois, A., Giuliani, A., Labanti, C., ... Barbiellini, G. (2010). Gamma-ray Localization of Terrestrial Gamma-ray Flashes by AGILE. In Agu fall meeting abstracts (Vol. 2010, p. AE11A-0330).

McTague, L. E., Cummer, S. A., Briggs, M. S., Connaughton, V., Stanbro, M., \& Fitzpatrick, G. (2015). A lightning-based search for nearby observationally dim terrestrial gamma ray flashes. J. Geophys. Res., 120(23), 12,003-12,017. Retrieved from https://agupubs.onlinelibrary.wiley.com/doi/abs/ 10.1002/2015JD023475 doi: https://doi.org/10.1002/2015JD023475 
Neubert, T., Ostgaard, N., Reglero, V., Blanc, E., Chanrion, O., Oxborrow, C., ... Bhanderi, D. (2019, 03). The ASIM Mission on the international space station. Space Science Reviews, 215. doi: 10.1007/s11214-019-0592-z

Østgaard, N., Gjesteland, T., Stadsnes, J., Connell, P. H., \& Carlson, B. (2008). Production altitude and time delays of the terrestrial gamma flashes: Revisiting the Burst and Transient Source Experiment spectra. J J. Geophys. Res., 113(A2), A02307. doi: 10.1029/2007JA012618

Pelliccioni, M. (2000). Overview of fluence-to-effective dose and fluence-to-ambient dose equivalent conversion coefficients for high energy radiation calculated using the fluka code. Radiation Protection Dosimetry, 88, 279-297. doi: 10.1093/oxfordjournals.rpd.a033046

Sarria, D., Kochkin, P., stgaard, N., Lehtinen, N., Mezentsev, A., Marisaldi, M., ... Eyles, C. (2019). The first terrestrial electron beam observed by the atmosphere-space interactions monitor. J. Geophys. Res., 124(12), 1049710511. Retrieved from https://agupubs.onlinelibrary.wiley.com/doi/ abs/10.1029/2019JA027071 doi: https://doi.org/10.1029/2019JA027071

Skeltved, A. B., stgaard, N., Carlson, B., Gjesteland, T., \& Celestin, S. (2014). Modeling the relativistic runaway electron avalanche and the feedback mechanism with geant4. Journal of Geophysical Research: Space Physics, 119(11), 91749191. Retrieved from https://agupubs.onlinelibrary.wiley.com/doi/abs/ 10.1002/2014JA020504 doi: https://doi.org/10.1002/2014JA020504

Skeltved, A. B., stgaard, N., Mezentsev, A., Lehtinen, N., \& Carlson, B. (2017). Constraints to do realistic modeling of the electric field ahead of the tip of a lightning leader. J. Geophys. Res., 122(15), 8120-8134. Retrieved from https://agupubs.onlinelibrary.wiley.com/doi/abs/10.1002/ 2016JD026206 doi: https://doi.org/10.1002/2016JD026206

Smith, D. M., Buzbee, P., Aron-Dine, S., Kelley, N. A., Holzworth, R. H., Hutchins, M. L., \& Dwyer, J. R. (2014). Constraining faint terrestrial gamma-ray flashes with stacking analyses. Fall Meeting, AGU, San Francisco, Calif., 17 Dec. 2014(AE33A-07).

Smith, D. M., Buzbee, P., Kelley, N. A., Infanger, A., Holzworth, R. H., \& Dwyer, J. R. (2016). The rarity of terrestrial gamma-ray flashes: 2. rhessi stacking analysis. Journal of Geophysical Research: Atmospheres, 121(19), 11,382- 
11,404. Retrieved from https://agupubs.onlinelibrary.wiley.com/doi/ abs/10.1002/2016JD025395 doi: https://doi.org/10.1002/2016JD025395

Smith, D. M., Dwyer, J. R., Hazelton, B. J., Grefenstette, B. W., Martinez-

McKinney, G. F. M., Zhang, Z. Y., ... Heckman, S. ～(2011). A terrestrial gamma ray flash observed from an aircraft. J. Geophys. Res., 116(D20). doi: doi.org/10.1029/2011JD016252

Stanley, M. A., Shao, X.-M., Smith, D. M., Lopez, L. I., Pongratz, M. B., Harlin, J. D., .. Regan, A. (2006). A link between terrestrial gamma-ray flashes and intracloud lightning discharges. Geophys. Res. Lett., 33(6), L06803. doi: 10.1029/2005GL025537

stgaard, N., Albrecthsen, K. H., Gjesteland, T., \& Collier, A. (2015). A new population of terrestrial gamma-ray flashes in the rhessi data. Geophys. Res. Lett., 42(24), 10,937-10,942. Retrieved from https://agupubs.onlinelibrary .wiley.com/doi/abs/10.1002/2015GL067064 doi: https://doi.org/10.1002/ 2015GL067064

stgaard, N., Gjesteland, T., Hansen, R. S., Collier, A. B., \& Carlson, B. The true fluence distribution of terrestrial gamma flashes at satellite altitude. J. Geophys. Res., 117(A3). Retrieved from https://agupubs .onlinelibrary.wiley.com/doi/abs/10.1029/2011JA017365 doi: https://doi.org/10.1029/2011JA017365

Tavani, M., Argan, A., Pesoli, A., Palma, F., Gerardin, S., Bagatin, M., ... Giommi, P. (2013). Possible effects on avionics induced by terrestrial gammaray flashes. $\quad$ Natural Hazards and Earth System Sciences, 13, 7023-. doi: 10.5194/nhess-13-1127-2013

Trompier, F., Fuller, N., Bonnotte, F., Desmaris, G., Musso, A., Cale, E., \& Bottollier-Depois, J.-F. (2014). Impact of tgf for aircrew dosimetry: analysis of continuous onboard measurements. EGU(14895).

Wilson, C. T. R. (1925). The acceleration of $\beta$-particles in strong electric fields such as those of thunderclouds. Proceedings of the Cambridge Philosophical Society, 22, 534. doi: 10.1017/S0305004100003236

Xu, W., Celestin, S., \& Pasko, V. P. (2012). Source altitudes of terrestrial gammaray flashes produced by lightning leaders. Geophys. Res. Lett., 39(8), L08801. doi: 10.1029/2012GL051351 